Check for updates

Cite this: RSC Adv., 2017, 7, 31428

\title{
Bio-based additives as renewable alternatives for polyvinylchloride formulations and application in paper coatings $\uparrow$
}

\begin{abstract}
Ellana Beard, ${ }^{a}$ Michelle Ledward ${ }^{b}$ and Natalia Sergeeva (D) *a
A series of bio-based additives derived from citric acid as a renewable chemical source were synthesised. The chemical composition and purity of 1-4 were confirmed by the combination of NMR, FTIR and MS. The thermal behaviour, stability and degradation pattern of the compounds 1-4 were investigated by TGA and DSC methods. PVC based formulations with compounds 1-4 were prepared through a simple mixing method. The formulations were treated at different temperatures $\left(130-210{ }^{\circ} \mathrm{C}\right)$ to investigate the potential of these materials in industrial curing settings. $L * a * b *$ data were used to monitor and to assess a colour change in the coated paper samples; this showed a correlation with degradation data of the pure compounds 1-4. SEM analysis of the final paper samples indicated that the compounds 1-4 show gas formation within the cellular structure; however compounds 3 and 4 result in a glossy smooth surface. This study showed that the compounds 3 and 4 exhibit promising properties in PVC formulations for application in industrial settings.
\end{abstract}

Received 3rd May 2017

Accepted 13th June 2017

DOI: 10.1039/c7ra04995a

rsc.li/rsc-advances

compounds to alternative materials and other plasticisers. Levelling agents, or stabilisers, are other additives used in many formulations, the most common of which are silicone surfactants. They are widely used in emulsions, sealants and coatings. ${ }^{19,23}$ In general, the higher the content of silicone, the lower the surface tension of the surfactant, ${ }^{24}$ resulting in high levels of silicone present in many PVC formulations. The major disadvantages of silicone compounds are their low solubility in aqueous solutions ${ }^{19}$ and hazardous implications. ${ }^{25}$ Due to these common side effects and toxicity classifications of siliconebased additives, alternative materials are highly sought after. ${ }^{26}$

Alternative, more sustainable, additives are selected on the basis of many criteria including low toxicity, compatibility with the host material, non-volatility, and expense. Plasticisers, used in plastics, are often based on esters of polycarboxylic acids, as these meet the required specifications. Citric acid is an inexpensive and renewable additive readily available from both synthetic and natural resources, such as fruits ${ }^{27}$ and bacteria. ${ }^{28}$ Citrates are, in general terms, cost effective, non-toxic and meet the listed specifications. They also provide water-solubility, which allows for greater diversity in formulation modifications. Furthermore, the green properties of the citrate derivatives are also essential, both in production and recycling to maintain the sustainability of the manufacturing process. Based on its availability and non-toxic nature, citric acid and its derivatives have been widely studied and used in the fields of resins, ${ }^{3}$ coatings and plasticisers, ${ }^{\mathbf{9}, 14}$ and cosmetics to name a few. However, citric acid is not suitable in all applications and therefore, modification of the compound is required. ${ }^{29}$ This work focuses on the use of citric acid derivatives as a strategy to 
improve the sustainability of chemical additives in PVC applications. In the following section the successful synthesis of a series of novel citric acid derivatives and their application within PVC polymer coatings are given. The coatings have been analysed for detrimental properties such as high colouration, thermal stability, surface defects and microstructure.

\section{Experimental}

Synthesis and characterisation of compounds 1-4 are described in the ESI. $\dagger$

\section{Preparation of the PVC polymer coating formulations (1-4)}

Each compound 1-4 was added to a commercial formulation in equivalent molar quantities of $0.161 \mathrm{mmol}$ per gram of plastisol. The mixture was stirred at speed 750 for $120 \mathrm{~s}$ in a Greaves ST-8 mechanical stirrer with radial turbine blade. A 200 micrometer coating of each sample was prepared on preheated (5 s at $210{ }^{\circ} \mathrm{C}$ ) Kaemplex LW 3 FSC Double Coated Peelable Duplex Paper $\left(140 \mathrm{~g} \mathrm{~m}^{-2}\right.$ ) using a Werner Mathis LTE-S Labcoater and heated at $130{ }^{\circ} \mathrm{C}$ for 30 seconds in a Werner Mathis Thermosol Oven, $220 \mathrm{~V}, 3$ phase, $60 \mathrm{~Hz}, 9 \mathrm{~kW}$. The procedure was repeated for each compound at each of the following temperatures: $130{ }^{\circ} \mathrm{C}, 150{ }^{\circ} \mathrm{C}, 170{ }^{\circ} \mathrm{C}, 190{ }^{\circ} \mathrm{C}$ and $210{ }^{\circ} \mathrm{C}$.

\section{Characterisation and instruments}

${ }^{1} \mathrm{H}$ - and ${ }^{13} \mathrm{C}-\mathrm{NMR}$ spectra of all samples were measured on a Bruker AVANCE-500 NMR spectrometer operating in the Fourier transform mode using $\mathrm{CDCl}_{3}$ as solvent. The phase transition behaviours of the samples were studied using a Q200 differential scanning calorimetry (DSC) analyser (TA Instruments, USA). The sample was crimped in an aluminum pan and heated at a rate of $5{ }^{\circ} \mathrm{C} \mathrm{min}^{-1}$ from ambient temperature to $300{ }^{\circ} \mathrm{C}$ under nitrogen atmosphere. Thermogravimetric analysis (TGA) of the samples was performed on a Q5000 thermal analyser (TA Instruments, USA) under air atmosphere, from room temperature to $300{ }^{\circ} \mathrm{C}$ at a heating rate of $20{ }^{\circ} \mathrm{C} \mathrm{min}^{-1}$. The morphology of the plastisol was observed using a Geol JSM 6610 Lv scanning electron microscope. Cross section samples were prepared using a Pilling Weck WECPREP Surgical Blade. Prior to SEM observation, the samples were sputter-coated with $30 \mathrm{~nm}$ gold, using a Quorum Q15OR S Coater, in order to improve the conductivity.

\section{Results and discussion}

\section{Synthesis and characterisation of citric derivatives}

Citric acid can be regarded as a versatile platform for structural modification, as its scaffold allows a variety of chemical transformations with various species. Citric acid and its esters are common reagents and are selected for use in the reaction with the hydrazine derivatives (hydrazine monohydrate and phenyl hydrazine). Citric acid reacts with both hydrazine monohydrate and phenyl hydrazine to yield compounds $\mathbf{1}$ and 2, respectively (Fig. 1).

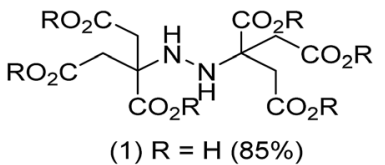

(1) $\mathrm{R}=\mathrm{H}(85 \%)$

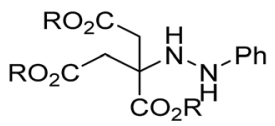

(2) $\mathrm{R}=\mathrm{H}(89 \%)$

(4) $\mathrm{R}=\mathrm{Et}(96 \%)$
Fig. 1 Synthesized acid 1, 2 and ester 3, 4 hydrazo citric derivatives.

Table 1 Significant peaks in the IR spectrum for the characterisation of compounds 1-4

\begin{tabular}{llll}
\hline Compound & C-N & N-H (bend) & N-H (stretch) \\
\hline $\mathbf{1}$ & 1184 & 1653 & 3436 \\
$\mathbf{2}$ & 1082 & 1602 & 3252 \\
$\mathbf{3}$ & 1022 & 1619 & 3497 \\
$\mathbf{4}$ & 1022 & 1601 & 3368
\end{tabular}

Triethyl citrate reacts similarly with the hydrazine monohydrate and the phenyl hydrazine yielding corresponding products 3-4. The excellent chemical purity and yields make this synthetic pathway highly practical allowing cost-efficient scale-up (50 g) of the compounds 1-4.

The characterisation of the citrate derivatives is carried out using a combination of analytical techniques (NMR, IR and MS). Significant peaks in the IR spectrum for the characterisation of hydrazo molecules account for a contemporaneous presence of the $\mathrm{C}-\mathrm{N}, \mathrm{N}-\mathrm{H}$ and $\mathrm{N}-\mathrm{N}$ stretching vibrations. All compounds 1-4 exhibit a strong peak in the region of 1000$1300 \mathrm{~cm}^{-1}(\mathrm{C}-\mathrm{N})$, the $\mathrm{N}-\mathrm{N}$ stretching vibration $\left(1600 \mathrm{~cm}^{-1}\right)$ and $\mathrm{N}-\mathrm{H}$ stretches $\left(2350\right.$ and $2700 \mathrm{~cm}^{-1}$ ) confirming the presence of the hydrazo group. The essential IR peaks for the characterisation of the novel compounds are listed in Table 1 . The ${ }^{1} \mathrm{H}$ NMR data of the materials 1-4 support the characterisation made by IR and highlight a shift in the peak corresponding to the aliphatic protons. A typical shift of 0.15-0.30 ppm from the corresponding hydroxyl-precursors is observed in hydrazo derivatives 1-4 indicating the successful conversion to the hydrazo group.

\section{Thermal behaviour, stability and decomposition pathway of compounds 1-4}

We have used thermal gravimetric analysis (TGA) and differential scanning calorimetry (DSC) to evaluate the thermal properties of compounds 1-4 as these techniques can be used to predict the behaviour of the additives within the coating formulation at various cure temperatures. Typical temperatures including the temperature at $10 \%$ mass loss in the TGA $\left(\mathrm{T}_{-10 \%}\right)$, the maximum thermal degradation temperature $\left(T_{\max }\right)$ from the $1^{\text {st }}$ derivative of the TGA (DTG), and the phase transition temperature in the DSC $\left(T_{\mathrm{DSC}}\right)$ are summarized in Table 2.

Differences in the thermal stability are observed between the acids 1, 2 and esters 3, 4 (Fig. 2a). For the ester compounds 3 and 4 , the thermal degradation based on TGA is a one-step process, characterised by $T_{\max }$, and occurs at a similar range of $188^{\circ} \mathrm{C}$ and $189^{\circ} \mathrm{C}$, respectively. These values of the maximum 
Table 2 TGA, DTG and DSC data for compounds 1-4

\begin{tabular}{llll}
\hline & \multicolumn{1}{c}{ TGA } & & $\frac{\text { DSC }}{2}$ \\
\cline { 2 - 3 } Compound & $T_{-10 \%}$ & $T_{\max }$ & $T_{\text {DSC }}$ \\
\hline $\mathbf{1}$ & 116 & 198 & 199 \\
$\mathbf{2}$ & 79 & 139,201 & 207 \\
$\mathbf{3}$ & 141 & 188 & 209 \\
$\mathbf{4}$ & 126 & 189 & 205
\end{tabular}

degradation temperatures are in a correlation with the values obtained from DSC analysis for the corresponding compounds $3\left(209^{\circ} \mathrm{C}\right)$ and $4\left(205^{\circ} \mathrm{C}\right)$.

In both cases, $T_{\max }$ and $T_{\mathrm{DSC}}$ are observed within the suitable melt viscosity range of PVC plastisol. Acid compounds $\mathbf{1}$ and 2 show an earlier onset of thermal degradation, comparing to the esters $\mathbf{3}$ and $\mathbf{4}$, and occur over two steps. The two-steps observed in compounds $\mathbf{1}$ and $\mathbf{2}$ may be due to the decarboxylation of the acids, which does not occur in the ester derivatives $\mathbf{3}$ and $\mathbf{4}$. Compound 1 exhibits 10\% mass loss at the lower temperature of $116{ }^{\circ} \mathrm{C}$, due to volatilisation of co-crystallised water, also observed as a small shoulder in the first derivative graph. However, $T_{\max }$ onset of the pyrolysis happens at the much higher temperature of $198^{\circ} \mathrm{C}$ and coherent with $T_{\mathrm{DSC}}=199^{\circ} \mathrm{C}$ (as observed in $\mathbf{3}$ and $\mathbf{4}$ ). In the case of the acid compound 2, its thermal degradation process can be divided into two distinct stages characterised by two values of $T_{\max }$. The first step occurs in the range of $100-160^{\circ} \mathrm{C}$, which is much lower than that of the other citrate derivatives, and accounts already for almost $70 \%$ mass loss. DSC data supports this finding showing a broad band $c a .100{ }^{\circ} \mathrm{C}$ wide within the same range, which may be attributed to the subsequent decarboxylation steps.

\section{PVC coating formulations, temperature dependency and colour correlation}

To study derivatives 1-4 within polymer matrix, the novel plastisols containing compounds $\mathbf{1 - 4}$ have been formulated to a standard specification, manufactured and analysed to determine the effect on coating efficiency, surface wetting and coating coverage. The formulations have been cured at $130{ }^{\circ} \mathrm{C}$, $150{ }^{\circ} \mathrm{C}, 170{ }^{\circ} \mathrm{C}, 190{ }^{\circ} \mathrm{C}$ and $210{ }^{\circ} \mathrm{C}$ to correspond with the melt viscosity range of the PVC plastisol. This allowed temperature dependency studies to be carried out for each of the materials. Table 3 shows $L^{*} a^{*} b^{*}$ and $\Delta E$ data for the thermally cured plastisols P1-P4 containing compounds 1-4. The $L^{*} a^{*} b^{*}$ values are given for the formulated plastisol cured at $130{ }^{\circ} \mathrm{C}$ and have been set as control samples $\mathbf{P} \mathbf{1}_{\mathbf{1 3 0}}-\mathbf{P} \mathbf{4}_{\mathbf{1 3 0}}$ to monitor temperature dependent colour change $(\Delta E)$ for each formulation (Fig. 2b). Sample $\mathbf{P 1}$ formulated with $\mathbf{1}$ shows a significant increase in $\Delta E$ between $170{ }^{\circ} \mathrm{C}, 190{ }^{\circ} \mathrm{C}$ and $210{ }^{\circ} \mathrm{C}$ curing temperatures (Fig. 2c), which coincides with the TGA and DSC data of the individual compound 1 . The yellow saturation $\left(b^{*}\right)$ in P1 increases from $130{ }^{\circ} \mathrm{C}$, evident in the TGA shoulder of $\mathbf{1}$ from $110^{\circ} \mathrm{C}$ upwards. The colour indexing coupled with the TGA data confirms that the full decomposition of compound 1 occurs within the range of $170-200{ }^{\circ} \mathrm{C}$.

The control sample $\mathbf{P 2} \mathbf{1}_{\mathbf{1 3 0}}$ shows a stronger initial colouration (Table 3), this is due to the lower decomposition temperature observed in the TGA of the compound 2 accounting for a $70 \%$ weight loss between $100-160^{\circ} \mathrm{C}$. Similarly, sample $\mathbf{P 2}$ shows a strong colour change from $170{ }^{\circ} \mathrm{C}$ to $210^{\circ} \mathrm{C}$ demonstrated by a significant increase in $\Delta E$. This corresponds to the second thermal decomposition step, which occurs within this $T$ range. With $\Delta E_{210}$ values of 22.54 and 30.85 , for $\mathbf{P 1}$ and $\mathbf{P 2}$ respectively, the colour changes observed are beyond the limit for corrections, such as bleaching, to be effective (Fig. 2b). This data concludes that at the temperatures above $175{ }^{\circ} \mathrm{C}$, strong colouration renders these additives unsuitable for use in colour sensitive coatings and applications.

In contrast, the ester derivatives 3 and $\mathbf{4}$ do not show a significant colour change during the heating process (Fig. 2b

Table $3 L * a * b *$ and $\Delta E$ values for compounds $1-4$ in thermally treated plastisol formulations $\mathrm{P} 1-\mathrm{P} 4$ at different curing temperatures

\begin{tabular}{|c|c|c|c|c|c|c|c|}
\hline \multirow[b]{2}{*}{ Entry } & \multicolumn{3}{|c|}{$130{ }^{\circ} \mathrm{C}$} & \multicolumn{4}{|l|}{$\Delta E$} \\
\hline & $L^{*}$ & $a^{*}$ & $b^{*}$ & $150^{\circ} \mathrm{C}$ & $170^{\circ} \mathrm{C}$ & $190^{\circ} \mathrm{C}$ & $210^{\circ} \mathrm{C}$ \\
\hline P1 & 93.95 & -0.27 & 0.43 & 1.61 & 4.55 & 10.01 & 22.19 \\
\hline P2 & 93.75 & -0.68 & 4.07 & 1.44 & 6.76 & 22.87 & 27.70 \\
\hline P3 & 94.43 & -0.08 & -0.39 & 0.40 & 0.33 & 0.31 & 0.74 \\
\hline P4 & 89.39 & 1.45 & 18.62 & 0.46 & 0.40 & 2.38 & 3.77 \\
\hline
\end{tabular}
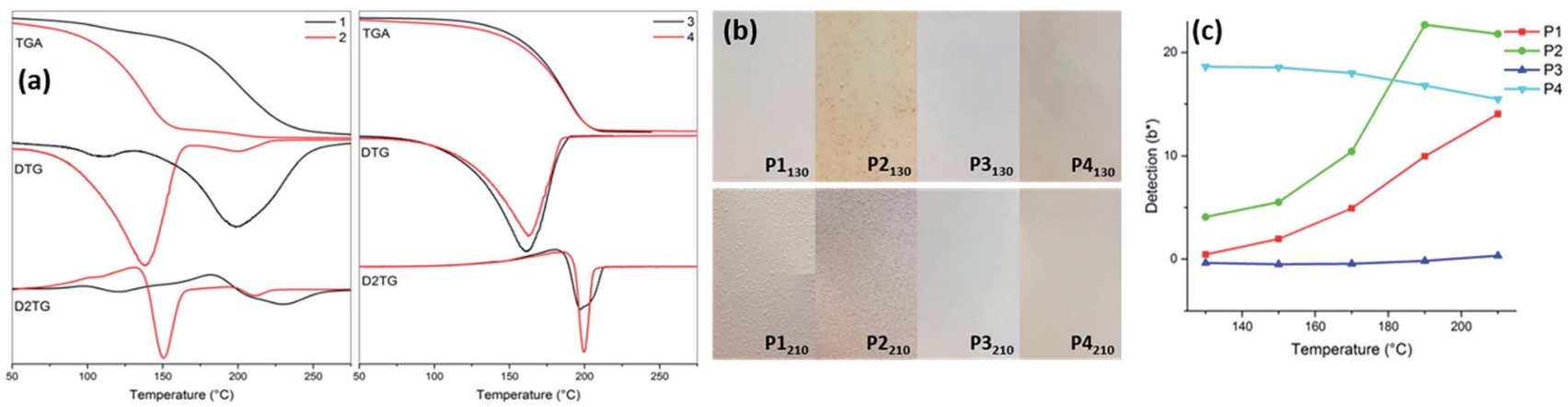

Fig. 2 (a) TGA, DTG and D2TG graphs of compounds $1-4$. (b) Photographs of the surface of the formulation coatings $P 1_{130}-P 4_{130}$ and $P 1_{210}-$ $\mathrm{P} 4_{210}$ showing the observed colour changes. (c) Graph of $b^{*}$ values for $\mathrm{P} 1_{130-210}, \mathrm{P} 2_{130-210}, \mathrm{P} 3_{130-210}$ and $\mathrm{P} 4_{130-210}$. 
and c). The $\Delta E$ values for formulated plastisol P3 (0.31-0.74) show that the colour change is negligible across the analysed temperature range $(\Delta E<1)$. Similarly, formulation $\mathbf{P 4}$ shows an insignificant colour change up to $170{ }^{\circ} \mathrm{C}$; however, a noticeable change in $\Delta E$ is observed at a higher temperature. $\Delta E_{210}$ shows a slight increase in colour intensity, conducive with $T_{\mathrm{DSC}} 205^{\circ} \mathrm{C}$. Unlike the compounds $\mathbf{1}$ and $\mathbf{2}$, the ester derivatives $\mathbf{3}$ and $\mathbf{4}$ are suitable for colour sensitive applications.

\section{Surface texture and microstructure}

The external and the internal cellular structure of the paper samples $\mathbf{P 1}_{210}-\mathbf{P 4} \mathbf{2 1 0}_{\text {a }}$, formulated with compounds 1-4 and cured at $210{ }^{\circ} \mathrm{C}$, are analysed with scanning electron microscopy (SEM). A standard 'control' formulation $\mathbf{P}_{\text {control }}$ has been prepared via the same method for comparisons. $\mathbf{P}_{\text {control }}$ presents an uneven surface (Fig. 3a), which is the result of irregularly sized gas pockets throughout the sample. The defects are observed across the sample surface ranging from 0.31-1.46 mm with the average defect size $c a .0 .80 \mathrm{~mm}$. Samples $\mathbf{P 1} \mathbf{1}_{\mathbf{2 1 0}}$ and $\mathbf{P 2} 2_{210}$ show a reduction in the average size of the gas bubbles observed on the surface of the coating, however the gas pockets are more unevenly distributed (Fig. 3a). Sample $\mathbf{P 1}_{210}$ shows an average defect size of $c a .0 .59 \mathrm{~mm}$. In the case of sample P2 2 , the unevenness caused by the gas bubbles consisted of both raised defects and craters (ESI Fig. 12†), generally of smaller size than seen in the control sample (Fig. 3c).

The distribution graph (Fig. 3b) clearly shows that all three samples exhibit a wide range in surface defect size. That said $\mathbf{P 1} 1_{210}$ and $\mathbf{P 2} 2_{210}$ show a higher concentration of defects within the region of $0.1-0.6 \mathrm{~mm}$ compared to $\mathbf{P}_{\text {control}}$, which displays a higher number of defects above $0.6 \mathrm{~mm}$. Improved distribution of the additive can result in a higher quality coating. The quantity of these gas bubbles increases as the temperature is increased, confirming that the colour and gas formation are both a direct result of thermal decomposition. Both of the ester mixtures $\mathbf{P 3}$ and $\mathbf{P 4}$ produced very smooth and evenly dispersed coatings. In the acid compounds $\mathbf{1}$ and $\mathbf{2}$ the main contributing force is hydrogen bonding around the $\mathrm{N}-\mathrm{H}$ donor site, as well as the HOOC- site in the carboxylic acid derivatives. Despite being significantly weaker than covalent bonds, hydrogen bonds exhibit strong dipole-dipole interactions creating stability within the system and thus contributing to a relatively high surface tension. The esterification of the carboxylic acid group (as in compounds 3 and 4 ) limits the available H-bonding sites and therefore reduces the surface tension effects, allowing the materials to act as levelling agents creating a smooth and glossy coating (Fig. 3a).

Cross section images provide information of the internal cellular structure, confirming that the surface defects are resultant of gas pockets within the coating. In the case of sample $\mathbf{P} \mathbf{1}_{210}$, the cross section analysis (Fig. 3c) indicates that the additive $\mathbf{1}$ hinders the distribution of the internal gas pockets as these are not evenly dispersed and exhibit a large cell size range (ESI Fig. 6 and $7 \dagger$ ). In comparison, $\mathbf{P}_{\text {control }}$ shows more evenly distributed gas bubbles, within a narrower cell size range (Fig. 3c).

In contrast to the rough uneven surface observed in the control, sample $\mathbf{P} \mathbf{3}_{\mathbf{2 1 0}}$ appeared to be smooth and even (Fig. 3a). The cross section micrograph of $\mathbf{P} \mathbf{3}_{210}$ shows that gas pockets are still formed in the formulation (Fig. 3c); however the pockets are smaller, with a narrow size range (Fig. 3d), and more evenly dispersed, thus not defecting the external surface. The distribution graph (Fig. 3d) shows that, in general, the internal cell sizes are below $200 \mu \mathrm{m} . \mathbf{P 3}_{\mathbf{2 1 0}}$ and $\mathbf{P} \mathbf{4}_{\mathbf{2 1 0}}$, in particular, exhibit no anomaly results with all cells between 50 and $150 \mu \mathrm{m}$. This data confirms that compounds $\mathbf{3}$ and $\mathbf{4}$ aid the even distribution of the formulation across the coating whilst inhibiting larger gas pockets' formation. This allows even distribution of small gas pockets throughout the coating, resulting in a smooth even surface ( $\mathbf{P 4}_{210}$ in ESI Fig. $\left.24 \dagger\right)$. Contrastingly, $\mathbf{P}_{\text {control }}, \mathbf{P 1}_{210}$ and $\mathbf{P 2} 2_{210}$ contain a number of larger gas pockets, the cross sections analysed show cells up to $450 \mu \mathrm{m}\left(\mathbf{P 1}_{\mathbf{2 1 0}}\right.$ contains larger pockets over $1 \mathrm{~mm}$ in diameter, Fig. 3c). These larger gas pockets contribute to the uneven defects observed on the coating

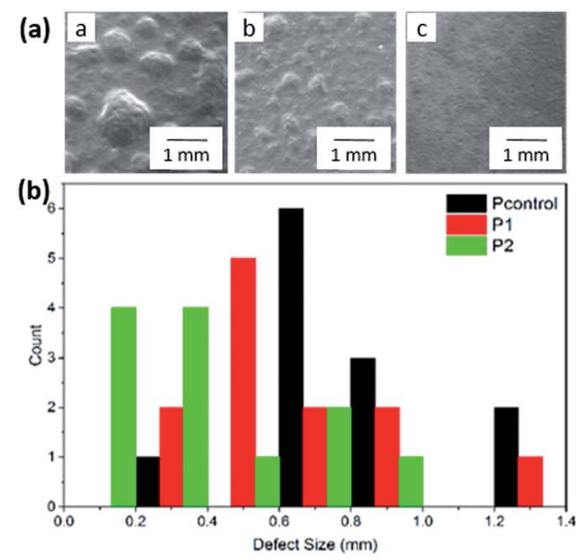

(c)

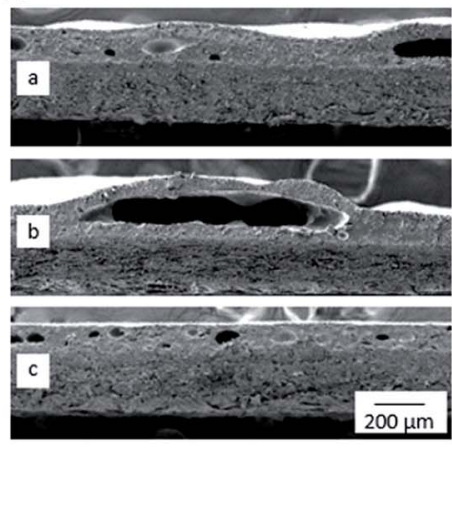

(d)

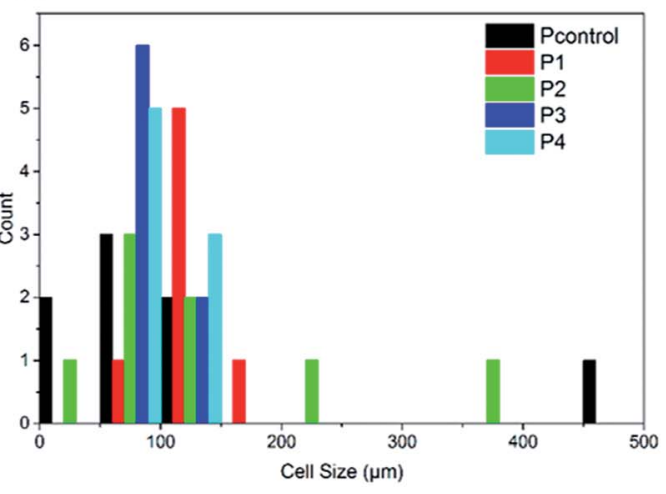

Fig. 3 (a) SEM micrographs of the surface of the plastisol formulation coatings prepared at $210{ }^{\circ} \mathrm{C}$ : a $\left(\mathrm{P}_{\text {control }}\right), \mathrm{b}\left(\mathrm{sample} \mathrm{P} 1_{210}\right)$ and $\mathrm{C}$ (sample $P 3_{210}$ ). (b) Distribution graph of SEM surface defect size data for $P_{\text {control, }} P 1_{210}$ and $P 2_{210}$. (c) Scanning electron micrographs of the cross section of plastisol formulation coatings: a $\left(\mathrm{P}_{\text {control }}\right), \mathrm{b}$ (sample $\left.\mathrm{P} 1_{210}\right)$ and $c$ (sample $\left.\mathrm{P} 3_{210}\right)$. (d) Distribution graph of SEM cross section cell size data for $\mathrm{P}_{\text {control, }} \mathrm{P}_{210}, \mathrm{P}_{210}, \mathrm{P}_{210}$ and $\mathrm{P}_{210}$. 
surface (Fig. 3a). These micrographs confirm that the distribution and regularity of the internal cell structure is fundamental to the surface appearance. Whilst all formulations show evidence of gas formation during heating, the cross section analysis provides evidence that compounds 3 and 4 inhibit the formation of large gas pockets which limits the disruption to the surface.

\section{Conclusions}

The citrate compounds 1-4 have been successfully synthesised and characterised. Synthesis of the compounds can be effectively scaled up to $50 \mathrm{~g}$ in excellent yields of up to $80 \%$. The TGA and DSC data confirm that thermal degradation of compounds 1-4, occurs within suitable range for implementation in PVC applications. PVC plastisols containing compounds 1-4 have been prepared and thermal stability of the final formulations have been tested at different curing temperatures. Thermal degradation data of the individual compounds 1, 2 and observed colour changes in the plastisol samples containing 1 and $2(\Delta E$, Table 3$)$ are in an excellent agreement supporting a thermal decomposition between $170{ }^{\circ} \mathrm{C}$ and $210{ }^{\circ} \mathrm{C}$ curing temperatures. The incorporation of the compounds 1-4 into commercial PVC plastisols directly affects the physical properties of the resultant coating. In the case of compounds 3 and 4 the increased gas dispersion coupled with decreased cellular size, observed in the SEM cross sections, is beneficial to the overall appearance of the coating surface. Furthermore, these compounds do not significantly affect the colouration of the sample surface, which is beneficial in many industrial processes.

\section{Acknowledgements}

The authors want to acknowledge G\&B Ltd UK (Grant number: RG.CHEM.103302) for their gracious financial and practical support. Mr Algy Kazlauciunas (University of Leeds) for assistance in TGA, DSC and SEM procedures.

\section{Notes and references}

1 C. C. Cheng, J. J. Huang, Z. S. Liao, S. Y. Huang, D. J. Lee and Z. Xin, Polym. Chem., 2017, 8, 1454.

2 A. Duereh, Y. Sato, R. L. Smith and H. Inomata, ACS Sustainable Chem. Eng., 2015, 3, 1881.

3 P. Gogoi, M. Boruah, S. Sharma and S. K. Dolui, ACS Sustainable Chem. Eng., 2015, 3, 261.

4 A. Codou, M. Moncel, J. G. van Berkel, N. Guigo and N. Sibirrazzuoli, Phys. Chem. Chem. Phys., 2016, 18, 16647.

5 L. Wei, N. M. Stark and A. G. McDonald, Green Chem., 2015, 17, 4800.

6 A. Gandini and T. M. Lacerda, Prog. Polym. Sci., 2015, 48, 1.
7 E. A. Quadrelli, G. C. Centi, J.-L. Duplan and S. Perathoner, ChemSusChem, 2011, 4, 1194.

8 T. Zhang, H. Zhong, Y. Qiu, X. Li and H. Zhang, J. Mater. Chem. A, 2016, 4, 16670.

9 X. Zhang, Y. Li, J. M. Hankett and Z. Chen, Phys. Chem. Chem. Phys., 2015, 17, 4472.

10 British Plastics Federation, PVC Explained, 2016, cited 2016, http:/www.bpf.co.uk/press/PVC_explained.as.px.

11 Z. Song, G. Liu, D. He, X. Pang, Y. Tong, Y. Wu, D. Yuan, Z. Liu and Y. Xu, Green Chem., 2016, 18, 5994.

12 K. W. Lee, J. W. Chung and S.-Y. Kwak, Green Chem., 2016, 18, 999.

13 Understanding the challenges and opportunities for the chemical sector, available from https:// europeanclimate.org/wp-content/uploads/2014/03/ECFEuropes-low-carbon-Transition-web1.pdf.

14 R. Tejasvi, M. Sharma and K. Upadhyay, Chem. Eng. J., 2015, 262, 875 .

15 Z. Jiang, K. Yao, Z. Du, J. Xue, T. Tang and W. Lui, Compos. Sci. Technol., 2014, 97, 74.

16 S. Swarup and C. K. Schoff, Prog. Org. Coat., 1993, 23, 1.

17 L. O. Kornum and H. K. Raaschou Nielsen, Prog. Org. Coat., 1980, 8, 275.

18 A. Vasantha Kumar, G. G. Redhi and R. M. Gengan, ACS Sustainable Chem. Eng., 2016, 4, 4951.

19 M. Owen, Properties and Applications of Silicones, in Advances in Silicones and Silicone-Modified Materials, ed. S. Clarson, M. Owen, S. Smith and M. Van Dyke, American Chemical Society, Washington DC, 2010.

20 D. F. Cadogan and C. J. Howick, Plasticizers, in Ullmann's Encyclopedia of Industrial Chemistry, Wiley-VCH, Weinheim, 2000.

21 M. P. Malveda, Chemical Economics Handbook Report on Plasticizers, 2015.

22 B. E. Erickson, Chem. Eng. News, 2015, 93, 11.

23 K. Ding, A. W. Pierpont, W. W. Brennessel, G. Lukat-Rodgers, K. R. Rodgers, T. R. Cundari, E. Bill and P. L. Holland, J. Am. Chem. Soc., 2009, 131, 9471.

24 A. J. O'Lenick, J. Surfactants Deterg., 2000, 3, 387.

25 European Chemicals Agency, Candidate list of substances of very high concern for authorisation, cited 13/04/2017, http:// echa.europa.eu/candidate-list-table/.

26 S. Das, S. J. Kalita, P. Bharali, B. K. Konwar, B. Das and A. J. Thakur, ACS Sustainable Chem. Eng., 2013, 1, 1530.

27 B. S. Chanukya, M. Prakash and N. K. Rastogi, J. Food Process. Preserv., 2016, 41, 12790.

28 L. P. S. Vandenberghe, C. R. Soccol, A. Pandey and J.-M. Lebeault, Braz. Arch. Biol. Technol., 1999, 42, 263.

29 S. Massimo, P. Bortolotti and M. Badali, Process for producing pre-expandable plastic beads and their use as structural elements for household appliances, EP250855A1, 2012. 